\title{
Patterns of diagnostic imaging and associated radiation exposure among long-term survivors of young adult cancer: a population-based cohort study
}

Corinne Daly', David R. Urbach 2,3,4, Thérèse A. Stukel ${ }^{3,4}$, Paul C. Nathan ${ }^{3,4,5}$, Wayne Deitel ${ }^{6}$, Lawrence F. Paszat ${ }^{3,4,7}$, Andrew S. Wilton ${ }^{3}$ and Nancy N. Baxter ${ }^{1,3,4^{*}}$

\begin{abstract}
Background: Survivors of young adult malignancies are at risk of accumulated exposures to radiation from repetitive diagnostic imaging. We designed a population-based cohort study to describe patterns of diagnostic imaging and cumulative diagnostic radiation exposure among survivors of young adult cancer during a survivorship time period where surveillance imaging is not typically warranted.

Methods: Young adults aged 20-44 diagnosed with invasive malignancy in Ontario from 1992-1999 who lived at least 5 years from diagnosis were identified using the Ontario Cancer Registry and matched 5 to 1 to randomly selected cancer-free persons. We determined receipt of 5 modalities of diagnostic imaging and associated radiation dose received by survivors and controls from years 5-15 after diagnosis or matched referent date through administrative data. Matched pairs were censored six months prior to evidence of recurrence.

Results: 20,911 survivors and 104,524 controls had a median of 13.5 years observation. Survivors received all modalities of diagnostic imaging at significantly higher rates than controls. Survivors received $C T$ at a 3.49-fold higher rate (95\% Confidence Interval [CI]:3.37, 3.62) than controls in years 5 to 15 after diagnosis. Survivors received a mean radiation dose of 26 milisieverts solely from diagnostic imaging in the same time period, a 4.57 -fold higher dose than matched controls ( $95 \% \mathrm{Cl}: 4.39,4.81$ ).
\end{abstract}

Conclusions: Long-term survivors of young adult cancer have a markedly higher rate of diagnostic imaging over time than matched controls, imaging associated with substantial radiation exposure, during a time period when surveillance is not routinely recommended.

\section{Background}

Epidemiologic evidence has established that exposure to ionizing radiation is a risk factor for leukemia and several solid cancers, with exposures at a younger age conferring a greater risk than later exposure [1-3]. Data suggest that acute exposure to 10-50 millisievert (mSv) or protracted exposure to $50-100 \mathrm{mSv}$ of $\mathrm{x}$ - or $\gamma$ -

\footnotetext{
* Correspondence: baxtern@smh.ca

Presented in part: Abstracts at the ASCO Annual Meeting in Chicago (June 2012) and the ASCO Quality Care Symposium in San Diego (December 2012).

${ }^{1}$ Department of Surgery, Li Ki Shing Knowledge Institute, St. Michael's Hospital, Toronto, Canada

${ }^{3}$ Institute for Clinical Evaluative Sciences, Toronto, Canada

Full list of author information is available at the end of the article
}

radiation infers an increased risk [4]. Studies have also demonstrated a positive association between diagnostic radiation and cancer risk [5-7]; repetitive computed tomography $(\mathrm{CT})$ imaging and exposure during young adulthood may be particularly harmful [8-12]. The radiation dose associated with a CT study does not pose immediate risks; however, patients undergoing repeated CT studies accumulate radiation exposure over time. Some authors estimate that 29,000 future cancers could be related to the CT scans performed in 2007 in the United States alone [13].

Approximately 10,000 young adults (aged 20-44) are diagnosed with cancer annually in Canada [14]. Young patients are more radiosensitive than older adults and 
recent evidence has demonstrated that genetic factors may further heighten the association between diagnostic radiation and cancer risk in some groups [7, 15] (although not all young adults may have an increased genetic risk for developing cancer). In the example of breast cancer, young carriers of the BCRA 1 and 2 mutations may experience an increased risk of breast cancer at radiation dose levels considerably lower than those associated with an increased breast cancer risk in other cohorts exposed to radiation [15].

Patients diagnosed with a malignancy at a young age who survive have a substantial life expectancy and cumulative exposure to diagnostic radiation will increase as they age. Patients may be exposed to low doses of radiation from various types of radiological studies used during initial diagnostic workup, and treatment monitoring. Additionally, surveillance guidelines for recurrence after initial treatment often rely on routine imaging (chest $x$-ray, CT) [16-19] for up to 5 years following treatment ( depending on malignancy and risk of recurrence) adding to lifetime radiation exposure. The routine use of diagnostic imaging for surveillance after 5 years is generally of little benefit since for most cancers late recurrence is uncommon [20-24], and routine imaging may not be superior to clinical examination and evaluation of symptoms [25-28]. Little is known about patterns of diagnostic imaging among cancer survivors and to our knowledge, no study has evaluated this on a population basis among a young adult population at risk for accumulated radiation exposure from repetitive imaging over their lifetime .

We designed this study to investigate the uptake of diagnostic imaging and estimate cumulative diagnostic radiation exposure among a cohort of long-term survivors of young adult cancer compared to non-cancer controls in Ontario, Canada.

\section{Methods}

The Research Ethics Board of St. Michael's Hospital, Toronto, Ontario, Canada approved the study.

\section{Study design and setting}

We designed a population-based retrospective cohort study using four data sources: the Ontario Cancer Registry (OCR), the Canadian Institute for Health Information Discharge Abstract Database (CIHI-DAD), the Ontario Health Insurance Plan (OHIP) database and the Registered Persons Database (RPDB).

OCR is a provincial cancer registry that has recorded all patients with incident cancers diagnosed in Ontario since 1964. Reporting to the OCR is provincially mandated and estimated to be $95 \%$ complete [29]. CIHIDAD contains information on all discharges from acute care hospitals and same day surgery units for residents of Ontario since April 1988. The OHIP database contains all claims for physicians and laboratory services provided to Ontario residents since 1991, essentially capturing the use of all physician services in Ontario. The RPDB is a roster of all individuals eligible for OHIP. All diagnostic codes in OCR are recorded according to the International Classification of Diseases.

\section{Selection of survivors}

We used the OCR to identify all young adults, aged 20-44 at diagnosis of incident invasive malignancy (Additional file 1: Table S1) between January 1st, 1992 and December 31st, 1999. Patients were excluded if they had a previous malignancy, died within 5 years from diagnosis, were eligible for OHIP less than 7 years after diagnosis date, or had evidence of recurrent disease within 5 years of diagnosis. Recurrence is not recorded in the OCR; we modified a previously validated algorithm [30] that considered diagnosis of metastatic disease, receipt of palliative care or new chemotherapy found in administrative data to be evidence of recurrence (Additional file 1: Table S2). The recurrence date was defined as the earliest date of any palliative, chemotherapy or metastatic codes identified.

\section{Selection of controls}

A cohort of matched controls was used to compare rates of imaging in survivors to the general population. Potential control subjects were selected from the general population using the RPDB, excluding those with a previous malignancy, matched to survivors by calendar year of birth, sex, and geographical region. Rates of diagnostic imaging in populations with cancer compared with the general population have showed differences based on these variables [31-33]. Potential controls were assigned a referent date corresponding to the date of the incident malignancy of their matched survivors; they were excluded if they died within 5 years of the referent date or if they became ineligible for OHIP in year 6 or 7 for reasons other than death. From the remaining potential controls, up to 5 were randomly selected without replacement for each survivor.

The cohort pairs were followed for a maximum of 15 years. Survivors who developed recurrent disease after 5 years of survivorship, along with their matched controls, were censored 6 months prior to the date of the first evidence of recurrence as the exact date of recurrence diagnosis was not obtainable. After 5-year survival, cohort pairs were additionally censored for death, end of OHIP eligibility or end of December 2010 for any pair member, whichever occurred first. 


\section{Diagnostic imaging utilization}

We identified OHIP professional billing codes [34] for CT (28 codes), plain radiography (171 codes), nuclear medicine (144 codes), MRI (11 codes) and diagnostic ultrasound (74 codes) (Additional file 1: Table S3). All CT (inpatient and outpatient) imaging is captured in OHIP. For other diagnostic imaging modalities, only outpatient imaging is captured. The date and number of diagnostic studies received by cohort members from the 5 th year of survival through year 15 after diagnosis/referent date were identified in the OHIP database. Ultrasounds for fetal assessment were excluded to control for potential different rates of pregnancy in survivors and controls. If multiple imaging studies were billed on the same day, we included all procedures. Abdominal and pelvic CTs billed on the same day were considered a single abdo-pelvic CT.

We calculated the mean number of diagnostic studies received per person year for years 5 through 15 after the diagnosis/referent date for each imaging modality for survivors and controls. We also identified the physician specialty responsible for ordering $\mathrm{CT}$ scans in our population.

\section{Radiation dose}

Effective dose is a commonly used metric providing a measure of harm from diagnostic radiation taking into account weighted averages of specific organ radiation dose according to the sensitivity of each organ to radiation [www.icrp.org/docs/Histpol.pfd]. We identified effective dose estimates for $\mathrm{CT}$, plain radiography and nuclear medicine studies from current radiology literature and standard dosing references [35-37]. (Additional file 1: Table S3) Effective dose estimates used in this study are comparable with the range of published estimates for Canada and the United States and remained consistent over the observation period [38, 39].

\section{Statistical analysis}

We calculated diagnostic imaging study rates as the number of diagnostic imaging studies per person-year of follow-up, overall, by type of imaging modality and by malignancy for survivors and controls. We used Poisson models for count data to compare rates of imaging studies in survivors versus controls, overall and by imaging modality, controlling for survivor status (survivor or control), malignancy type and socioeconomic status (SES), using an offset, the person-years of follow-up. We accounted for matching among survivors and controls by including a term for matched pairs. We did not find evidence of over-dispersion in the count data.

Mean and median cumulative effective dose (CED) received were calculated on an individual basis by tallying individual effective doses for all radiation-associated imaging studies received in years 5-15. CED was highly skewed, so it was log transformed for analysis. We compared the CED between survivors and controls using log-linear regression, adjusting for SES and malignancy type, and adjusting for differential follow-up times among pairs by weighting by person-years. Regression estimates were transformed back to the original scale and interpreted on a relative scale, presented by overall cancer and stratified by malignancy type with $95 \%$ confidence intervals (CI).

We used SAS version 9.2 (SAS Institute, Cary, NC) for all statistical analyses. All statistical tests were 2-sided and significance was set at $P<0.05$.

\section{Results}

Between January 1st, 1992 and December 31st, 1999, 32,895 Ontarians age 20 to 44 were diagnosed with an invasive malignancy. Of these, 20,911 (63.6 \%) were included in the analysis, with reasons for exclusion illustrated in Fig. 1. We identified 104,524 matched controls. The cohort distribution by sex and diagnoses are in Table 1. Survivors and controls had a median follow-up time of 13.5 (interquartile range $[\mathrm{IQR}]=11.5,15.6$ ) years from date of diagnosis/reference. According to our administrative data algorithm, 1,199 (7.2\%) of YAS had evidence of recurrence after 5-year survival. Overall, 1,270 (6.1\%) survivors died in the observation period of the study (5-15 years after diagnosis/referent date); 836 (4.0\%) had evidence of recurrence and were censored at a median of 1.5 years before death. 429 survivors (2.1\%) died without evidence of recurrence, compared to 1,600 $(1.5 \%)$ deaths in the control group.

\section{Patterns of diagnostic imaging}

A total of 375,293 imaging studies were performed among survivors in the observation period; most were plain radiographs (48\%), diagnostic ultrasounds (31\%), or CT scans (12\%) (Table 2). The number of diagnostic studies received by survivors varied by malignancy type. For example, the mean number of $\mathrm{CT}$ scans was highest in survivors of non-Hodgkin lymphoma (NHL) (0.73 CT scans per person year) and lowest for survivors of thyroid cancer (0.15 CT scans per person year) (Table 2). Hematologists/oncologists were responsible for ordering the majority of CT scans (37 \%) among survivors, while primary care practitioners were responsible for ordering the majority (38\%) among controls. A small proportion of CT scans were ordered by emergency family physicians among survivors (3\%) compared to $9 \%$ ordered among controls.

Survivors received all types of diagnostic studies at significantly higher rates than sex-, age- and geographicallymatched controls. Overall, survivors received CT at an adjusted 3.49-fold higher rate than controls (rate ratio 


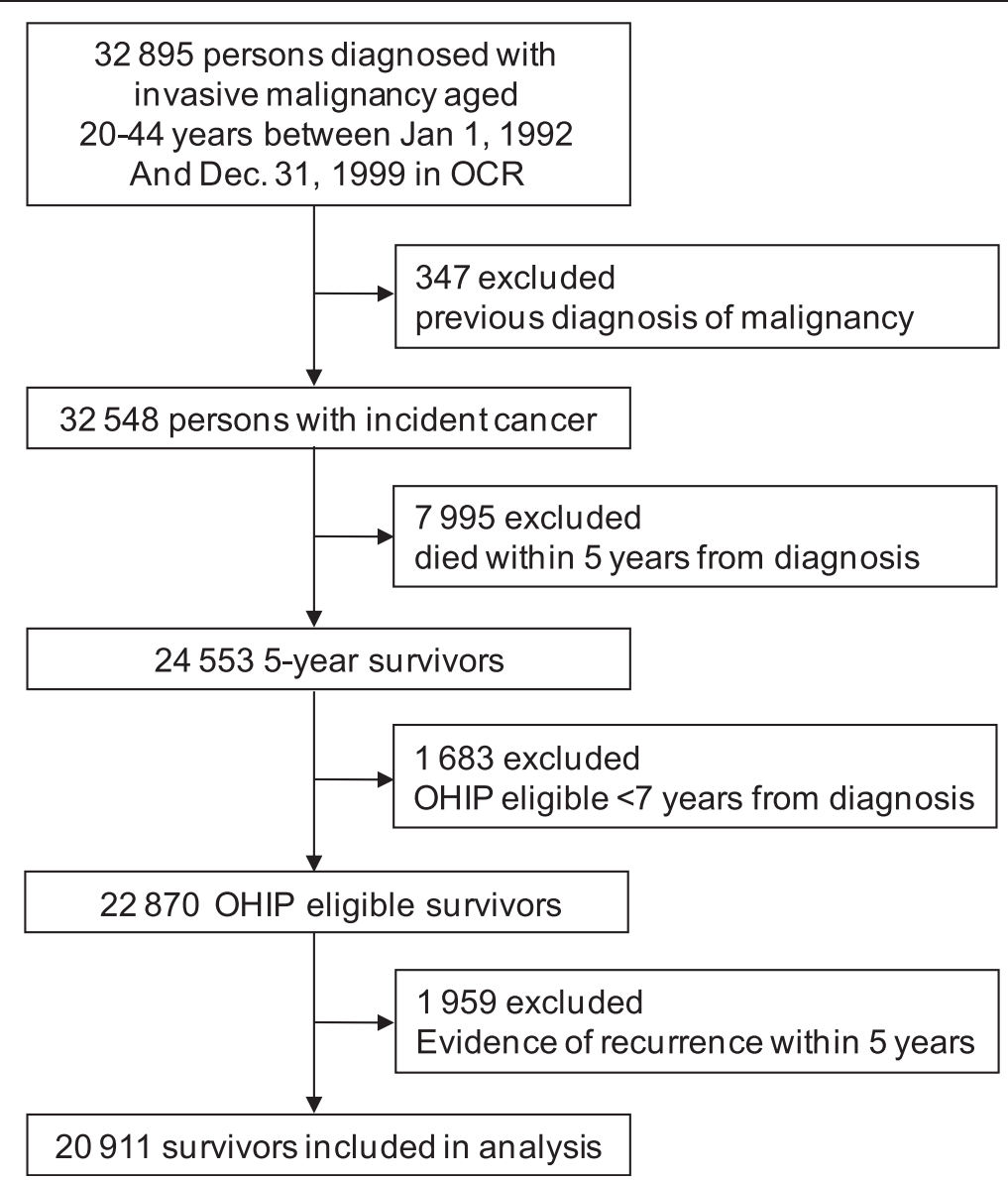

Fig. 1 Cohort of survivors of young adult cancer with exclusions. OCR = Ontario Cancer Registry, OHIP = Ontario Health Insurance Plan

$[R R]=3.49,95 \%$ CI: 3.37, 3.62, Fig. 2a). When stratified by malignancy type, all groups had a significantly higher rate of CT scanning than matched controls. Rate ratios ranged from 1.93 (thyroid, $95 \%$ CI: 1.73, 2.16) to 8.42 (NHL, 95 \% CI: 7.48, 9.48) (Fig. 2a). Rates of plain radiography (Fig. 2b) and nuclear medicine tests (Fig. 2c) were also higher in YAS as compared with controls.

Imaging studies not associated with radiation exposure were also more common in the survivor group. Survivors underwent ultrasound at a rate 1.4-fold higher (95 \% CI: 1.38,1.43) (Fig. 2d) and MRI at a rate 2.35-fold higher (95 \% CI: 2.24, 2.45) than matched controls (Fig. 2e). The rate of MRI was low in all malignancy groups except survivors of brain malignancies $(\mathrm{RR}=$ 22.04, 95 \% CI: 19.21, 25.28; not shown in Fig 2e).

\section{Diagnostic radiation exposure}

Survivors received a mean CED of $26.3 \mathrm{mSv}$ (median = $8.4 \mathrm{mSv}$ ) in years 5-15 after diagnosis, whereas controls received a mean dose of $10.7 \mathrm{mSv}$ (median $=2.0 \mathrm{mSv}$ ) (Table 3). Overall, $16 \%$ of survivors received a CED of $50 \mathrm{mSv}$ or greater in this 10-year period (Table 3), with some malignancy groups receiving particularly high doses. Among survivors of non-Hodgkin lymphoma (NHL), almost a third exceeded the $50 \mathrm{mSv}$ threshold and $15 \%$ received $\geq 100 \mathrm{mSv}$ in a 10 -year period. Almost a quarter of survivors of gastrointestinal cancer and a fifth of survivors of breast, urologic, Hodgkin's lymphoma and leukemia malignancies received $\geq 50 \mathrm{mSv}$. After adjusting for covariates, survivors received a 4.57 -fold higher cumulative dose than matched controls $(95 \% \mathrm{CI}$ : $4.39,4.81$ ) in years $5-15$ after diagnosis (Fig. 3). When stratified by malignancy type, the CED of survivors ranged from 1.89-fold (melanoma, $95 \%$ CI: 1.63, 2.17) to 11.70 -fold higher (HL, $95 \% \mathrm{CI}: 9.49,14.44$ ) than matched controls (Fig. 3).

\section{Discussion}

In this population-based cohort study, we showed that long-term survivors of young adult malignancies (greater than 5 years from diagnosis) received all types of diagnostic imaging, including CT associated with high effective doses of radiation, at significantly higher rates than controls in a time period where routine diagnostic imaging is not generally part of surveillance. Approximately one fifth of survivors received over $50 \mathrm{mSv}$ of 
Table 1 Description of survivors of young adult malignancies and matched controls cohort at diagnosis/referent dates

\begin{tabular}{|c|c|c|}
\hline & $\begin{array}{l}\text { Survivors } \\
(n=20,911)\end{array}$ & $\begin{array}{l}\text { Controls } \\
(n=104,524)\end{array}$ \\
\hline Age, mean (SD) & $36(6.3)$ & $36(6.3)$ \\
\hline Median Follow-up Years ${ }^{\mathrm{a}}$ (IQR) & $13.5(5.0,18.0)$ & $13.5(5.0,18.0)$ \\
\hline \multicolumn{3}{|l|}{ Sex } \\
\hline Male & $6,801(32.3)$ & $33,997(32.3)$ \\
\hline Female & $14,110(67.7)$ & $70,527(67.7)$ \\
\hline \multicolumn{3}{|l|}{ Malignancy Type } \\
\hline Breast & $4581(21.9)$ & - \\
\hline Gynecologic $^{\mathrm{b}}$ & $2782(13.3)$ & - \\
\hline Thyroid & $2388(11.4)$ & - \\
\hline Melanoma & $2088(10.0)$ & - \\
\hline Testicular & $1390(6.6)$ & - \\
\hline Non-Hodgkin Lymphoma & $1277(6.1)$ & - \\
\hline Hodgkin Lymphoma & $1072(5.1)$ & - \\
\hline Urologic & $895(4.3)$ & - \\
\hline Other & $887(4.2)$ & - \\
\hline Colorectal & $785(3.8)$ & - \\
\hline Head \& Neck & $768(3.7)$ & - \\
\hline Brain & $632(3.0)$ & - \\
\hline Bone \& Soft-tissue & $463(2.2)$ & - \\
\hline Chest \& Lung & $345(1.6)$ & - \\
\hline Leukemia & $284(1.4)$ & - \\
\hline Upper Gastrointestinal & $274(1.3)$ & - \\
\hline Received Radiation & $6,517(32.1)$ & \\
\hline Evidence of Recurrence & $1,199(7.2)$ & - \\
\hline Died $^{c}$ & $1,270(6.1)$ & $1,600(1.5)$ \\
\hline \multicolumn{3}{|l|}{ Income Quintile } \\
\hline 1 (lowest) & $3,983(19.0)$ & $20,709(19.8)$ \\
\hline 2 & $4,082(19.5)$ & $20,701(19.8)$ \\
\hline 3 & $4,176(20.0)$ & $21,084(20.2)$ \\
\hline 4 & $4,425(21.2)$ & $21,604(20.7)$ \\
\hline 5 (highest) & $4,245(20.3)$ & $20,426(19.5)$ \\
\hline
\end{tabular}

Percentages reported in parenthesis, except for age and median follow -up time

${ }^{a}$ From date of diagnosis/reference.

Includes ovarian, uterine and cervical malignancies.

${ }^{C}$ After 5-year survival.

Abbreviations: SD, standard deviation; IQR, interquartile range

diagnostic radiation, with some groups, such as survivors of lymphoma, gastrointestinal, leukemia and urologic malignancies, receiving particularly high doses. The survivor cohort had no evidence of recurrence based on administrative data for 5 years after diagnosis and survivors were censored 6 months before any evidence of recurrence; therefore the excess imaging in survivors was unlikely to be related to the diagnosis of actual recurrence.
Few studies have investigated the uptake of diagnostic imaging among cancer survivors. These have focused generally on a specific type of radiologic investigation (e.g. mammography) [40], older patients [41] or earlier years of survival $[42,43]$. Although recommendations for surveillance for recurrence after a primary cancer vary according to malignancy type, CT (when recommended) is used routinely when the risk of recurrence is highest, in general, during the first 5 years of survivorship [16, 44]. Routine surveillance is not recommended after 5-year survival for any malignancy based on current guidelines $[16,17,45,46]$. While diagnostic imaging may be relied upon to detect recurrence after 5 years of recurrence-free survival, studies in both pediatric and adult patients with HL have suggested that relapses are symptomatic and that routine $\mathrm{CT}$, in addition to being expensive, has poor specificity and provides minimal overall survival benefit $[47,48]$. We found that the recurrence-free survivors of $\mathrm{HL}$ in our cohort received an average of 1 CT scan every 2 years in years 5-15 after diagnosis.

The estimates of diagnostic radiation exposure from this study are limited to years following 5-years from initial diagnosis, so many persons will have been exposed to considerably higher doses after considering imaging for initial diagnosis and evaluation and radiotherapy for primary treatment. Some persons may also be more susceptible to the effects of radiation, reinforcing the importance to minimize any exposure when possible. Survivors of gastrointestinal, urologic and leukemia malignancies in the current study were exposed to high doses of diagnostic radiation with approximately one fifth of survivors reaching a $50 \mathrm{mSv}$ threshold within a 10 year time period. Notably, $15 \%$ of NHL survivors were exposed to at least $100 \mathrm{mSv}$ in the same time period. Survivors of testicular, upper gastrointestinal and lymphomas had at least a 4-fold higher rate of CT than controls. Even some survivors with a very low risk of recurrence, such as thyroid cancer, had more than a 2-fold higher rate of CT than controls. It is possible that this level of imaging may be appropriate; indications for diagnostic studies were not available in the administrative data used for this study. Hematologists/oncologists were responsible for ordering the majority of CT scans among survivors in this study. There were fewer scans ordered by emergency family physicians among survivors $(3 \%)$ than controls $(9 \%)$, suggesting that high CT rates among survivors are unlikely to be related to emergency care. However, identifying high rates of imaging highlights the need for future research directed at identifying potential elective diagnostic studies and ability to select alterative imaging modalities or non-imaging strategies to reduce radiation exposure whenever possible. 
Table 2 Mean number of diagnostic imaging studies received per person year, years 5-15 after diagnosis/referent dates, stratified by imaging modality and malignancy type

\begin{tabular}{|c|c|c|c|c|c|c|c|c|c|c|}
\hline \multirow[b]{2}{*}{ Malignancy Type } & \multicolumn{2}{|l|}{ CT } & \multicolumn{2}{|c|}{ Plain Radiography } & \multicolumn{2}{|c|}{ Nuclear Medicine } & \multicolumn{2}{|l|}{$\mathrm{MRI}$} & \multicolumn{2}{|c|}{ Ultrasound } \\
\hline & Survivors & Controls & Survivors & Controls & Survivors & Controls & Survivors & Controls & Survivors & Controls \\
\hline All Malignancies & 0.30 & 0.08 & 1.02 & 0.63 & 0.12 & 0.06 & 0.09 & 0.04 & 0.65 & 0.47 \\
\hline Thyroid & 0.15 & 0.08 & 0.80 & 0.62 & 0.12 & 0.06 & 0.06 & 0.04 & 0.87 & 0.57 \\
\hline Melanoma & 0.17 & 0.07 & 0.67 & 0.57 & 0.06 & 0.06 & 0.06 & 0.04 & 0.50 & 0.43 \\
\hline Gynecologic $^{a}$ & 0.21 & 0.09 & 0.87 & 0.71 & 0.08 & 0.07 & 0.05 & 0.04 & 0.71 & 0.58 \\
\hline Bone \& Soft-tissue & 0.23 & 0.07 & 1.00 & 0.48 & 0.09 & 0.04 & 0.11 & 0.03 & 0.52 & 0.41 \\
\hline Head \& Neck & 0.25 & 0.09 & 0.76 & 0.53 & 0.09 & 0.07 & 0.13 & 0.03 & 0.42 & 0.37 \\
\hline Brain & 0.26 & 0.08 & 0.58 & 0.50 & 0.06 & 0.05 & 0.65 & 0.03 & 0.39 & 0.84 \\
\hline Breast & 0.32 & 0.10 & 1.70 & 0.84 & 0.22 & 0.08 & 0.10 & 0.04 & 0.85 & 0.59 \\
\hline Colorectal & 0.33 & 0.08 & 0.87 & 0.62 & 0.09 & 0.07 & 0.05 & 0.04 & 0.64 & 0.42 \\
\hline Chest \& Lung & 0.33 & 0.10 & 1.13 & 0.60 & 0.09 & 0.06 & 0.04 & 0.03 & 0.43 & 0.41 \\
\hline Leukemia & 0.34 & 0.07 & 0.91 & 0.49 & 0.09 & 0.06 & 0.06 & 0.04 & 0.60 & 0.73 \\
\hline Urologic & 0.34 & 0.09 & 0.99 & 0.55 & 0.14 & 0.07 & 0.08 & 0.04 & 0.80 & 0.38 \\
\hline Testicular & 0.40 & 0.07 & 0.68 & 0.34 & 0.06 & 0.04 & 0.03 & 0.03 & 0.29 & 0.20 \\
\hline $\mathrm{HL}$ & 0.45 & 0.07 & 0.88 & 0.41 & 0.09 & 0.04 & 0.06 & 0.03 & 0.49 & 0.37 \\
\hline Upper Gl & 0.45 & 0.09 & 0.80 & 0.58 & 0.11 & 0.08 & 0.07 & 0.04 & 0.64 & 0.43 \\
\hline $\mathrm{NHL}$ & 0.73 & 0.09 & 0.90 & 0.54 & 0.11 & 0.06 & 0.07 & 0.04 & 0.56 & 0.41 \\
\hline
\end{tabular}

ancludes cervical, uterine and ovarian malignancies

Abbreviations: CT, computed tomography; MRI, magnetic resonance imaging; $\mathrm{HL}$, Hodgkin lymphoma; Gl, gastrointestinal; NHL, non-Hodgkin lymphoma

Although controversial, a number of epidemiologic studies have found significant associations between diagnostic radiation and the incidence of cancer $[12,15,49$, 50], highlighting the potential for harm associated with repetitive exposure to diagnostic imaging and CT in particular. Cancer patients receiving repetitive diagnostic and treatment monitoring imaging studies are at risk of high cumulative exposure in a short period of time. For example, $16 \%$ of survivors in the current study received $50 \mathrm{mSv}$ or more in a 10-year period. Survivors who received radiation therapy for primary treatment $(30 \%)$ are also at an additional risk of secondary carcinogenesis due to radiation exposure $[51,52]$. The potential for harm associated with radiation exposure is cumulative; as survivors age and continue to be imaged, small effective doses will accumulate to even higher life-time exposures. Many survivors have had substantial effective doses from recommended surveillance CT scans up to 5 years posttreatment, emphasizing the importance of minimizing imaging after 5-year recurrence-free survival, when possible.

\section{Limitations}

We used administrative data to identify receipt of imaging and therefore, could not determine the indication for imaging studies. Many studies may have been ordered for investigation of symptoms, but the symptoms were not due to disease recurrence. The OCR does not collect data on cancer recurrence, therefore we relied on an algorithm based on administrative codes. While a small number of survivors with recurrence may not have been detected by our algorithm, the rate of death without recurrence in survivors $(2.1 \%)$ was similar to the overall death rate of controls (1.5\%), indicating our algorithm successfully identified recurrent disease. Finally, because dosing metrics for imaging investigations were not available, we were not able to calculate absorbed doses and instead used effective dose. However, the use of a different metric would not influence the magnitude of difference found in exposure between survivors and controls.

The population-based and comprehensive data used for our study provided a unique opportunity to evaluate patterns of diagnostic imaging in all survivors in the province. Due to the lack of population-based health services data for similar groups of patients in many jurisdictions, our study would be difficult to replicate elsewhere, increasing the importance and relevance of our findings.

\section{Implications for future research}

Determining the optimal use of imaging among survivors of young adult cancer is challenging; while these individuals are at risk of recurrence and second malignancies, these risks vary according to malignancy type and must be balanced against the risk of cumulative radiation exposure. Although a higher rate of imaging in some survivors as compared to the general population may be appropriate, we found an increased rate for 


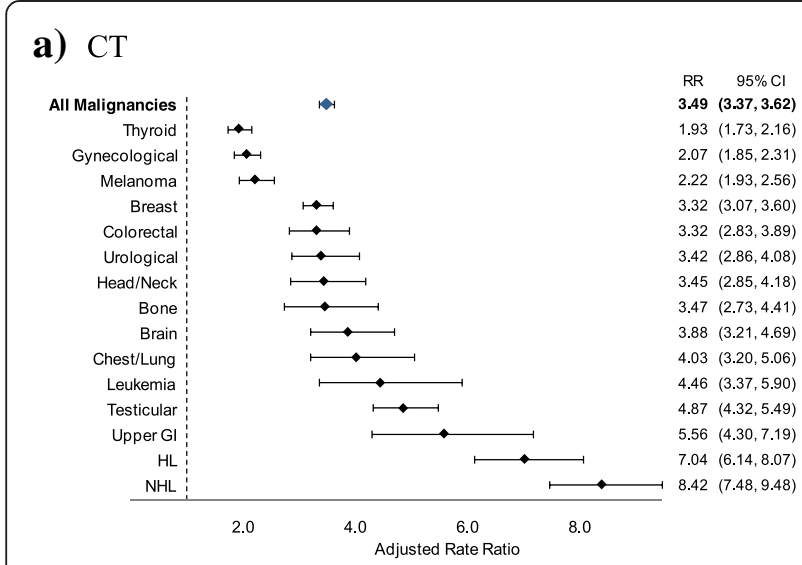

c) Nuclear Medicine

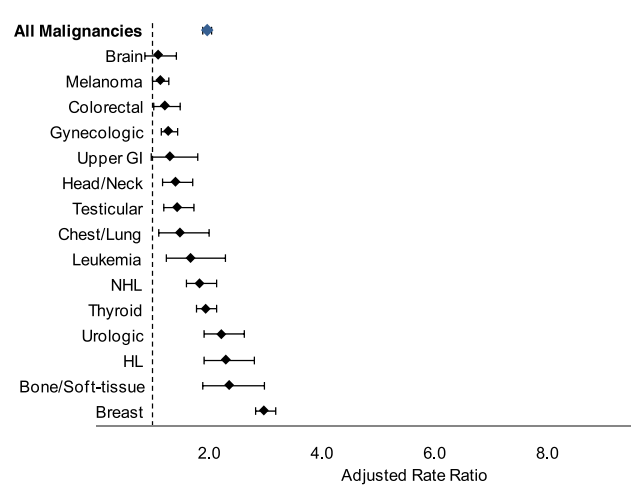

e) MRI

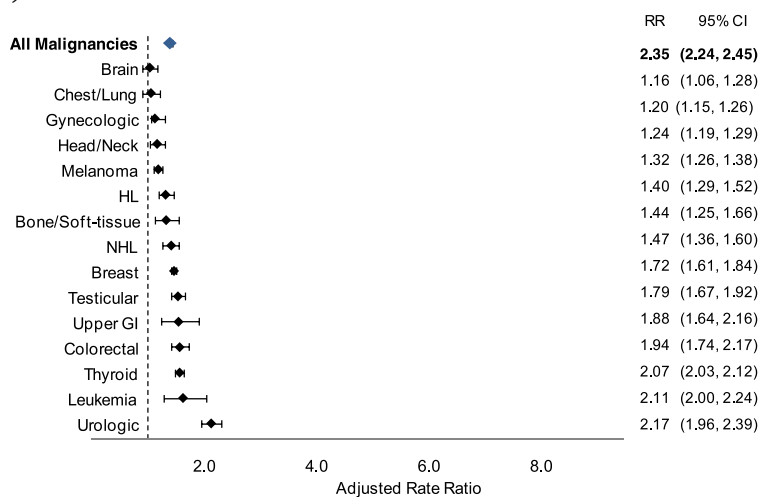

b) Plain Radiography

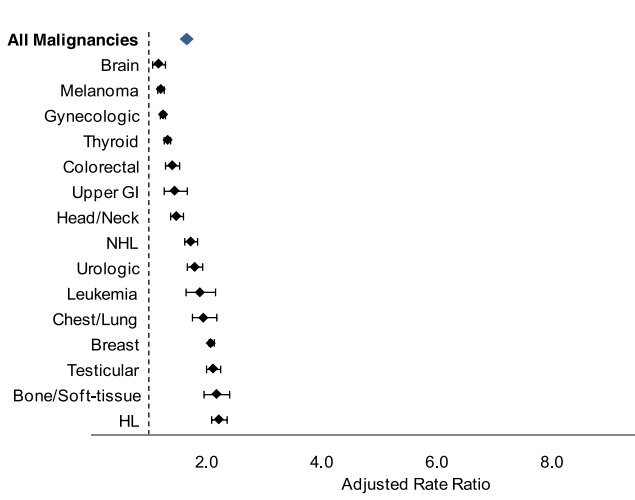

$1.66(1.64,1.69)$

$1.20(1.15,1.26)$

$1.20(1.15,12$

$1.32(1.26,1.38)$

$1.40(1.29,1.52)$

$1.44(1.25,1.66)$

$1.47(1.36,1.60)$

$1.72(1.61,1.84)$

$1.79(1.67,1.92)$

$1.88(1.64,2.16)$

$1.94(1.74,2.17)$

$2.07(2.03,2.12)$

$2.11(2.00,2.24)$

$2.17(1.96,2.39)$ $2.21(2.08,2.35)$

d) Ultrasound

RR $95 \% \mathrm{Cl}$

$\begin{array}{ll}1.97 & (\mathbf{1 . 8 9}, \mathbf{2 . 0 4}) \\ 1.10 & (0.85,1.41)\end{array}$

$1.10(0.85,1.41)$

$1.14(1.00,1.29)$

$1.22(1.01,1.48)$

$1.28(1.15,1.43)$

$1.31(0.96,1.79)$

$1.41(1.16,1.71)$

$1.44(1.20,1.73)$

$1.49(1.11,2.00)$

$1.68(1.24,2.29)$

$1.84(1.59,2.12)$

$1.95(1.77,2.13)$

$2.23(1.91,2.79$

$2.31(1.91,2.79)$

$2.37(1.89,2.97)$

$2.99(2.82,3.18)$

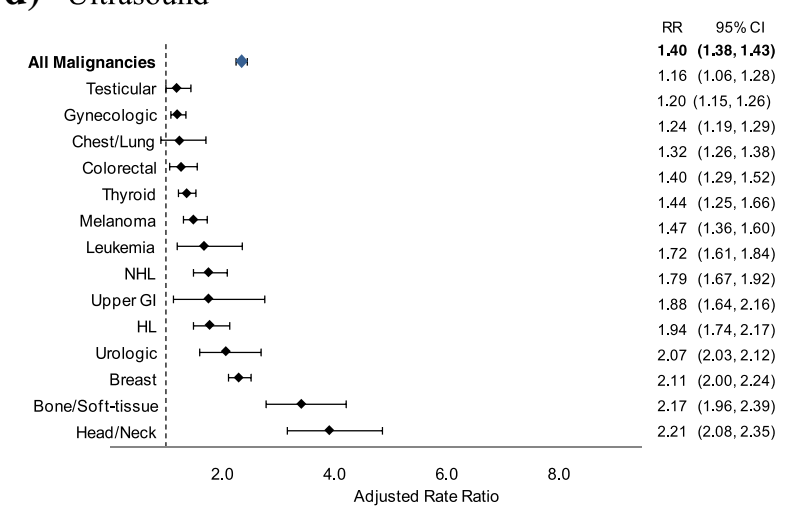

Fig. 2 Adjusted rate ratios of diagnostic imaging associated with radiation (a-c) and not associated with radiation (d-e) received by young adult survivors of cancer compared to non-cancer controls in years 5-15 after diagnosis, by malignancy type. Note: RR of MRI for brain malignancy not shown in (e): $\mathrm{RR}=22.04,95 \% \mathrm{Cl}: 19.21,25.28$. $\mathrm{RR}=$ rate ratio, $\mathrm{Cl}=$ confidence interval, $\mathrm{CT}=$ computed tomography, $\mathrm{MRI}=$ magnetic resonance imaging, $\mathrm{Gl}=$ gastrointestinal, $\mathrm{HL}=$ Hodgkin lymphoma, $\mathrm{NHL}=$ non-Hodgkin lymphoma

survivors extending up to 15 years after diagnosis for all malignancies and for all imaging modalities, indicating likely over-use of imaging in these patients. Strategies to reduce radiation exposure in survivors, including (when possible) the substitution of diagnostic procedures not associated with radiation, such as ultrasound, and the cessation of surveillance after 5 years should be considered. Educational interventions among physicians and patients that encourage good stewardship in the use of imaging, particularly the use of imaging associated with significant radiation exposure, should be explored.

\section{Conclusions}

Our study showed that survivors of young adult malignancies receive $\mathrm{CT}$ imaging studies and associated radiation at significantly higher rates than the general population during a time period where surveillance imaging is not typically recommended. 
Table 3 Mean effective dose received by survivors and controls with proportion of survivors receiving 50 and 100 mSv in years 5 through 15 after diagnosis/referent dates, stratified by malignancy type

\begin{tabular}{|c|c|c|c|c|c|c|c|}
\hline \multirow[b]{3}{*}{ Malignancy Type } & \multirow[b]{3}{*}{$\mathrm{n}$} & \multicolumn{2}{|c|}{ Mean Effective Dose, mSv } & \multicolumn{4}{|c|}{ Survivors Receiving Effective Dose } \\
\hline & & \multicolumn{2}{|l|}{ Dose, mSv } & \multicolumn{4}{|l|}{$\overline{n(\%)}$} \\
\hline & & Survivors & Controls & $50 \mathrm{mSv}$ & & $100 \mathrm{~m}$ & \\
\hline All Malignancies & 20911 & 26.3 & 10.7 & 3333 & $(15.9)$ & 1314 & $(6.3)$ \\
\hline Breast & 4581 & 34.4 & 13.0 & 909 & $(19.8)$ & 386 & $(8.4)$ \\
\hline Gynecologic $^{a}$ & 2782 & 19.6 & 11.2 & 308 & $(11.1)$ & 120 & $(4.3)$ \\
\hline Thyroid & 2388 & 18.3 & 10.0 & 258 & $(10.8)$ & 60 & $(2.5)$ \\
\hline Melanoma & 2088 & 14.9 & 9.9 & 166 & $(8.0)$ & 60 & $(2.9)$ \\
\hline Testicular & 1390 & 23.4 & 7.8 & 241 & $(17.3)$ & 57 & $(4.1)$ \\
\hline $\mathrm{NHL}$ & 1277 & 46.0 & 10.2 & 364 & (28.5) & 193 & $(15.1)$ \\
\hline $\mathrm{HL}$ & 1072 & 31.8 & 7.2 & 211 & $(19.7)$ & 98 & $(9.1)$ \\
\hline Urologic & 895 & 31.6 & 11.2 & 175 & (19.6) & 76 & $(8.5)$ \\
\hline Colorectal & 785 & 26.4 & 12.1 & 140 & $(17.8)$ & 50 & $(6.4)$ \\
\hline Head \& Neck & 768 & 22.5 & 11.4 & 101 & $(13.2)$ & 40 & $(5.2)$ \\
\hline Brain & 632 & 16.3 & 9.4 & 47 & (7.4) & 8 & $(1.3)$ \\
\hline Bone \& Soft-tissue & 463 & 20.8 & 7.9 & 64 & (13.8) & 24 & $(5.2)$ \\
\hline Chest \& Lung & 345 & 28.2 & 11.3 & 66 & $(19.1)$ & 29 & $(8.4)$ \\
\hline Leukemia & 284 & 26.8 & 8.9 & 55 & (19.4) & 28 & $(9.9)$ \\
\hline Upper Gl & 274 & 36.7 & 12.0 & 68 & $(24.8)$ & 25 & $(9.1)$ \\
\hline
\end{tabular}

ancludes cervical, uterine and ovarian malignancies.

Abbreviations: mSv, miliSieverts; NHL, non-Hodgkin lymphoma; HL, Hodgkin lymphoma; Gl, gastrointestinal.

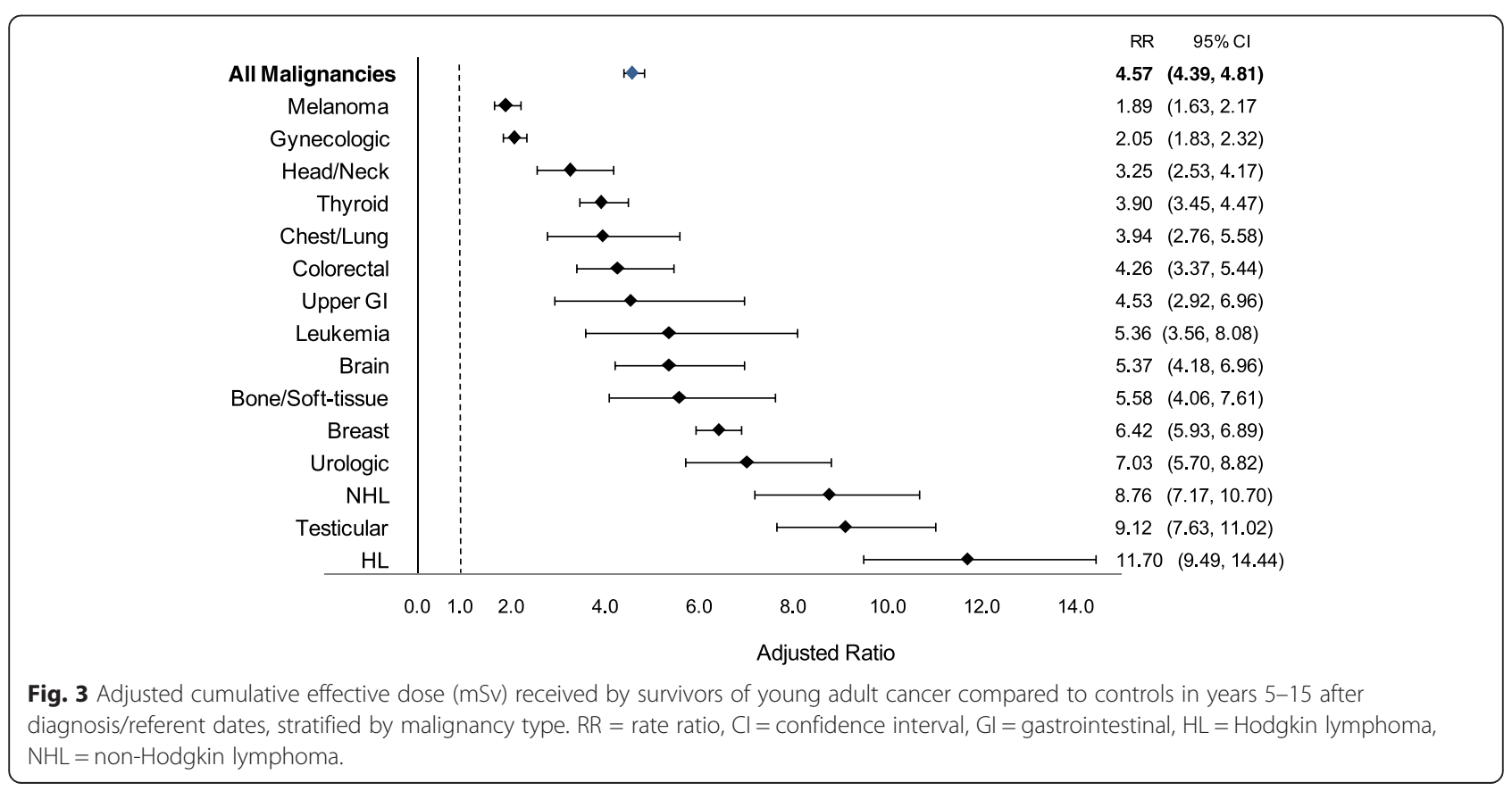




\section{Additional file}

Additional file 1: Table S1. International classification of disease (ICD)-9 codes and descriptions of malignancy types. Table S2. Administrative data codes used for identifying evidence of recurrent disease in young adult cancer survivors. Table S3. Ontario Health Insurance Plan (OHIP) professional fee codes for plain radiography, nuclear medicine, computed tomography, ultrasound and magnetic resonance imaging studies and effectives dose estimates for imaging studies associated with diagnostic radiation used in this study. (PDF $92 \mathrm{~kb}$ )

\section{Abbreviations}

CED: cumulative effective dose; CIHI-DAD: Canadian Institute for Health Information Discharge Abstract Database; CT: computed tomography; HL: Hodgkin lymphoma; Gl: Gastrointestinal; MRI: Magnetic resonance imaging; mSv: Millisievert; NHL: Non-Hodgkinlymphoma; OCR: Ontario Cancer Registry; OHIP: Ontario Health Insurance Plan; RPDB: Registered Persons Database; RR: Rate ratio; SES: Socioeconomic status.

\section{Competing interests}

The authors declare that they have no competing interests.

\section{Authors' contributions}

CD was responsible for the design of the study, data collection, assembly and integrity, statistical analysis, interpretation of data, and drafting of the manuscript. DU and PN contributed to study design and conception and interpretation of findings. WD and LP assisted with assembly of data and interpretation of findings. AW and TS contributed to data assembly and performed statistical analyses. NB was responsible for study design and conception, integrity of data and interpretation of findings. All authors read and approved the final manuscript.

\section{Acknowledgements}

This study was funded by a Canadian Institutes of Health Research (CIHR) Operating Grant (Funding Reference 86590) and Early Researchers Award from the Ontario Ministry of Economic Development and Innovation. Dr. Nancy Baxter is supported by a Cancer Care Ontario Research Chair Award. The funding sources had no role in the design or conduct of the study; collection, management, analysis or interpretation of the data; or preparation, review or approval of the manuscript. This study was supported by the Institute for Clinical Evaluative Sciences (ICES), which is funded by an annual grant from the Ontario Ministry of Health and Long-Term Care (MOHLTC). The opinions, results and conclusions reported in this paper are those of the authors and are independent from the funding sources. No endorsement by ICES or the Ontario MOHLTC is intended or should be inferred.

\section{Author details}

'Department of Surgery, Li Ki Shing Knowledge Institute, St. Michael's Hospital, Toronto, Canada. ${ }^{2}$ Department of Surgery, University Health Network, Toronto, Canada. ${ }^{3}$ Institute for Clinical Evaluative Sciences, Toronto, Canada. ${ }^{4}$ Institute of Health Policy, Management and Evaluation, University of Toronto, Toronto, Canada. ${ }^{5}$ Division of Haematology/Oncology, The Hospital for Sick Children, Toronto, Canada. ${ }^{6}$ Department of Radiology, St. Michael's Hospital, Toronto, Canada. ${ }^{7}$ Department of Radiation Oncology, Sunnybrook Health Sciences Center, Toronto, Canada.

\section{Received: 28 July 2014 Accepted: 27 July 2015}

\section{Published online: 03 September 2015}

\section{References}

1. Preston DL, Ron E, Tokuoka S, Funamoto S, Nishi N, Soda M, et al. Solid cancer incidence in atomic bomb survivors: 1958-1998. Radiat Res. 2007;168(1):1-64.

2. Thompson DE, Mabuchi K, Ron E, Soda M, Tokunaga M, Ochikubo S, et al. Cancer Incidence in Atomic Bomb Survivors. Part II: Solid Tumors, 1958-1987. Radiat Res. 1994;137(2s):S17-67.

3. Preston DL, Kusumi S, Tomonaga M, Izumi S, Ron E, Kuramoto A, et al. Cancer Incidence in Atomic Bomb Survivors. Part III: Leukemia, Lymphoma and Multiple Myeloma, 1950-1987. Radiat Res. 1994;137(2s):S68-97.
4. Brenner DJ, Doll R, Goodhead DT, Hall EJ, Land CE, Little JB, et al. Cancer risks attributable to low doses of ionizing radiation: Assessing what we really know. Proc Natl Acad Sci. 2003;100(24):13761-6.

5. Boice JD, Preston D, Davis FG, Monson RR. Frequent Chest X-Ray Fluoroscopy and Breast Cancer Incidence among Tuberculosis Patients in Massachusetts. Radiat Res. 1991:125(2):214-22.

6. Eisenberg MJ, Afilalo J, Lawler PR, Abrahamowicz M, Richard H, Pilote L. Cancer risk related to low-dose ionizing radiation from cardiac imaging in patients after acute myocardial infarction. Can Med Assoc J. 2011;183(4):430-6.

7. Myles P, Evans S, Lophatananon A, Dimitropoulou P, Easton D, Key T, et al. Diagnostic radiation procedures and risk of prostate cancer. $\mathrm{Br} J$ Cancer. 2008;98(11):1852-6.

8. Brenner DJ, Hall EJ. Computed tomography-an increasing source of radiation exposure. N Engl J Med. 2007;357(22):2277-84.

9. Brenner DJ. Should we be concerned about the rapid increase in $C T$ usage? Rev Environ Health. 2010;25(1):63-8

10. Kleinerman RA. Cancer risks following diagnostic and therapeutic radiation exposure in children. Pediatr Radiol. 2006;36 Suppl 2:121-5.

11. Smith-Bindman R, Lipson J, Marcus R, Kim K-P, Mahesh M, Gould R, et al. Radiation dose associated with common computed tomography examinations and the associated lifetime attributable risk of cancer. Arch Intern Med. 2009:169(22):2078-86.

12. Pearce MS, Salotti JA, Little MP, McHugh K, Lee C, Kim KP, et al. Radiation exposure from CT scans in childhood and subsequent risk of leukaemia and brain tumours: a retrospective cohort study. Lancet. 2012;380(9840):499-505.

13. Berrington de Gonzalez A, Mahesh M, Kim K-P, Bhargavan M, Lewis R, Mettler $F$, et al. Projected cancer risks from computed tomographic scans performed in the United States in 2007. Arch Intern Med. 2009;169(22):2071-7.

14. Cancer Care Ontario: Cancer in Young Adults in Canada, Toronto, Canada; 2006. ISBN 0-921325-10-X (print), ISBN 0-921325-11-8 (pdf).

15. Pijpe A, Andrieu N, Easton DF, Kesminiene A, Cardis E, Noguès $C$, et al. Exposure to diagnostic radiation and risk of breast cancer among carriers of BRCA1/2 mutations: retrospective cohort study (GENE-RAD-RISK). Br Med J. 2012;345, e5660

16. National Comprehensive Cancer Network. NCCN Clinical Practice Guidelines in Oncology: Hodgkin Lymphoma. Version I. 2012.

17. Grunfeld E, Dhesy-Thind S, Levine M. Clinical practice guidelines for the care and treatment of breast cancer: follow-up after treatment for breast cancer (summary of the 2005 update). Can Med Assoc J. 2005;172(10):1319-20.

18. National Comprehensive Cancer Network. NCCN Clinical Practice Guidelines in Oncology: Testicular Cancer. 2012. Version I.

19. National Comprehensive Cancer Network. NCCN Clinical Practice Guidelines in Oncology: Non-Hodgkin's Lymphomas. 2013. Version I.

20. Larouche JF, Berger F, Chassagne-Clement C, Ffrench M, Callet-Bauchu E, Sebban $\mathrm{C}$, et al. Lymphoma recurrence 5 years or later following diffuse large B-cell lymphoma: clinical characteristics and outcome. J Clin Oncol. 2010;28(12):2094-100.

21. Provencio M, Salas C, Millan I, Cantos B, Sanchez A, Bellas C. Late relapses in Hodgkin lymphoma: a clinical and immunohistochemistry study. Leuk Lymphoma. 2010;51(9):1686-91.

22. Saphner T, Tormey DC, Gray R. Annual hazard rates of recurrence for breast cancer after primary therapy. J Clin Oncol. 1996;14(10):2738-46.

23. Daugaard G, Gundgaard MG, Mortensen MS, Agerbaek M, Holm NV, Rorth $M$, et al. Surveillance for stage I nonseminoma testicular cancer: outcomes and long-term follow-up in a population-based cohort. J Clin Oncol. 2014;32(34):3817-23

24. Seo SI, Lim SB, Yoon YS, Kim CW, Yu CS, Kim TW, et al. Comparison of recurrence patterns between $</=5$ years and $>5$ years after curative operations in colorectal cancer patients. J Surg Oncol. 2013;108(1):9-13.

25. Rueth NM, Cromwell KD, Cormier JN. Long-term Follow-up for Melanoma Patients: Is There Any Evidence of a Benefit? Surg Oncol Clin N Am. 2015;24(2):359-77.

26. Montgomery DA, Krupa K, Cooke TG. Follow-up in breast cancer: does routine clinical examination improve outcome? A systematic review of the literature. Br J Cancer. 2007;97(12):1632-41.

27. Pivot X, Asmar L, Hortobagyi GN, Theriault R, Pastorini F, Buzdar A. A retrospective study of first indicators of breast cancer recurrence. Oncology. 2000;58(3):185-90. 
28. Rojas MP, Telaro E, Russo A, Moschetti I, Coe L, Fossati R, et al. Follow-up strategies for women treated for early breast cancer. Cochrane Database Syst Rev. 2005;1:Cd001768.

29. Robles SC, Marrett LD, Clarke EA, Risch HA. An application of capturerecapture methods to the estimation of completeness of cancer registration. J Clin Epidemiol. 1988;41(5):495-501.

30. Tan J. The Processes of Care after Colorectal Cancer Surgery in Ontario. Toronto: University of Toronto; 2008.

31. Pearce MS, Salotti JA, McHugh K, Kim KP, Craft AW, Lubin J, et al. Socioeconomic variation in CT scanning in Northern England, 1990-2002. BMC Health Serv Res. 2012;12:24.

32. Smith-Bindman R, Miglioretti DL, Johnson E, Lee C, Feigelson HS, Flynn M, et al. Use of Diagnostic Imaging Studies and Associated Radiation Exposure for Patients Enrolled in Large Integrated Health Care Systems, 19962010Diagnostic Imaging and Radiation Exposure. JAMA. 2012;307(22):2400-9.

33. Fazel R, Krumholz HM, Wang Y, Ross JS, Chen J, Ting HH, et al. Exposure to low-dose ionizing radiation from medical imaging procedures. N Engl J Med. 2009;361(9):849-57

34. Ontario Ministry of Health and Long-term Care. Schedule of Benefits for Physician Services under the Health Insurance Act. 2010. [http:// www.health.gov.on.ca/english/providers/program/ohip/sob/physserv/ physserv_mn.html]. Accessed Jan 25, 2011.

35. Columbia University Health and Safety. Dose Estimates for Nuclear Medicine Scans Available at: [http://ehs.columbia.edu/Dosimetry\%20Help/ NMDoseEstimates.html\#Adult] and Pediatric Dose Estimates from ICRP 106. Accessed March 20, 2012.

36. Mettler Jr FA, Huda W, Yoshizumi TT, Mahesh M. Effective doses in radiology and diagnostic nuclear medicine: a catalog. Radiology. 2008;248(1):254-63.

37. Stabin MG. RADAR Medical Procedure Radiation Dose Calculator. Stanford Dosimetry [http://www.doseinfo-radar.com/RADARDoseRiskCalc.html]. Accessed April 9, 2012

38. United Nations Scientific Committee on the Effects of Atomic Radiation. Report of the United Nations Scientific Committee on the Effects of Atomic Radiation to the General Assembly, vol. I. New York, New York, Report: UNSCEAR; 2000.

39. Stern S. Nationwide evaluation of x-ray trends (NEXT): Tabulation and graphical summary of 2000 survey of computed tomography. Frankfort: Conference of Radiation Control Program Directors; 2007.

40. Keating NL, Landrum MB, Guadagnoli E, Winer EP, Ayanian JZ. Factors related to underuse of surveillance mammography among breast cancer survivors. J Clin Oncol. 2006;24(1):85-94.

41. Field TS, Doubeni C, Fox MP, Buist DSM, Wei F, Geiger AM, et al. Under utilization of surveillance mammography among older breast cance survivors. J Gen Intern Med. 2008;23(2):158-63.

42. van Walraven C, Fergusson D, Earle C, Baxter N, Alibhai S, MacDonald B, et al. Association of diagnostic radiation exposure and second abdominalpelvic malignancies after testicular cancer. J Clin Oncol. 2011;29(21):2883-8.

43. Hodgson DC, Grunfeld E, Gunraj N, Del Giudice L. A population-based study of follow-up care for Hodgkin lymphoma survivors: opportunities to improve surveillance for relapse and late effects. Cancer. 2010;116(14):3417-25.

44. Chung $P$, Mayhew $M$, Warde $P$, Winquist $E$, Lukka $H$, Members of the Genitourinary Cancer Disease Site Group. Management of Stage I Seminoma: Guideline Recommendations. Program in Evidence-Based Care: A Cancer Care Ontario Program; 2008:Evidence-based series \#3-18: Section 11.

45. Elit L, Fung-Kee-Fung M, Oliver T, Gynecology Cancer Disease Site Group. Follow-up for women after treatment for cervical cancer: guidelines recommendations. Program in Evidence-Based Care: A Cancer Care Ontario Program; 2009: Evidence-based series \#4-16: Section 11.

46. National Comprehensive Cancer Network. NCCN Clinical Practice Guidelines in Oncology: Thyroid Carcinoma. 2012. Version 2.

47. Dryver ET, Jernstrom H, Tompkins K, Buckstein R, Imrie KR. Follow-up of patients with Hodgkin's disease following curative treatment: the routine CT scan is of little value. Br J Cancer. 2003;89(3):482-6.

48. Voss SD, Chen L, Constine LS, Chauvenet A, Fitzgerald TJ, Kaste SC, et al. Surveillance Computed Tomography Imaging and Detection of Relapse in Intermediate- and Advanced-Stage Pediatric Hodgkin's Lymphoma: A Report From the Children's Oncology Group. J Clin Oncol. 2012;30(21):2635-40.

49. Yaffe MJ, Mainprize JG. Risk of radiation-induced breast cancer from mammographic screening. Radiology. 2011;258(1):98-105.

50. Mathews JD, Forsythe AV, Brady Z, Butler MW, Goergen SK, Byrnes GB, et al. Cancer risk in 680000 people exposed to computed tomography scans in childhood or adolescence: data linkage study of 11 million Australians. $\mathrm{Br}$ Med J. 2013;346.

51. Hall EJ, Wuu CS. Radiation-induced second cancers: the impact of 3D-CRT and IMRT. Int J Radiat Oncol Biol Phys. 2003;56(1):83-8.

52. Maddams J, Parkin DM, Darby SC. The cancer burden in the United Kingdom in 2007 due to radiotherapy. Int J Cancer. 2011;129(12):2885-93.

\section{Submit your next manuscript to BioMed Central and take full advantage of:}

- Convenient online submission

- Thorough peer review

- No space constraints or color figure charges

- Immediate publication on acceptance

- Inclusion in PubMed, CAS, Scopus and Google Scholar

- Research which is freely available for redistribution 